\title{
Kuesioner Online Sebagai Media Feedback Terhadap Pelayanan Akademik pada STMIK Prabumulih
}

\author{
Muchlis', Andi Christian², Mariana Puspa Sari ${ }^{3}$ \\ Sistem Informasi - STMIK Prabumulih \\ J1. Patra No 50 Kelurahan Sukaraja Kec. Prabumulih Selatan. Telp. (0713) 322418 \\ e-mail: ${ }^{1}$ muchlis1078@gmail.com, ${ }^{2}$ andichristian918@ gmail.com, ${ }^{3}$ marianapuspasari27@ gmail.com
}

\begin{abstract}
Abstrak
Perguruan tinggi harus memberikan pelayanan yang baik terhadap kebutuhan mahasiswa dan dosen. Umpan balik pelayanan akademik perlu dievaluasi. Evaluasi pelayanan yang telah dilakukan pada STMIK Prabumulih adalah dengan menyebarkan kuesioner secara konvensional. Kendala penggunaan kuesioner secara konvensional, yaitu perhitungan yang dilakukan secara manual. Hal ini menimbulkan adanya kesalahan dalam perhitungan dan pemasukan data. STMIK Prabumulih juga harus menyediakan kuesioner dalam bentuk kertas. Mahasiswa maupun dosen merasa enggan untuk menjawab kuesioner dalam bentuk kertas. Untuk mengatasi permasalahan tersebut, maka perlu dibangun sistem informasi kuesioner online berbasis website sehingga responden dapat mengisi kuesioner di mana pun dan kapan pun. Metode yang digunakan dalam pengembangan sistem adalah metode waterfall dengan tahapan system engineering, analysis, design, coding, testing, dan maintenance. Pengujian sistem menggunakan pengujian black box. Hasil dari pengujian black box menunjukkan keseluruhan kebutuhan fungsional dapat berjalan dengan baik sesuai dengan kebutuhan dan sistem dapat berjalan dengan baik.
\end{abstract}

Kata kunci: Pelayanan Akademik, Kuesioner Online, Website, Metode Waterfall.

\begin{abstract}
Higher education must provide good service for the needs of students and lecturers. The return of academic services needs to be evaluated. Service evaluation that has been done on Prabumulih's STMIK by converting conventional questionnaires. The obstacle to using a conventional questionnaire is a calculation that is done manually. Data that causes errors in calculations and entering data. STMIK Prabumulih also has to provide a questionnaire in paper form. Students and lecturers receive questions in paper form. To overcome this problem, an online web-based questionnaire system needs to be built so that respondents can fill out questionnaires wherever and whenever. The method used in system development is the waterfall method with System Engineering, Analysis, Design, Encoding, Testing, and Maintenance. System testing uses Black Box testing. The results of black box testing show that all functional requirements can run well according to the needs and the system can run well.
\end{abstract}

Keywords: Academic Services, Online Questionnaire, Website, Waterfall Method.

\section{Pendahuluan}

Sebuah lembaga pendidikan seperti perguruan tinggi harus memberikan pelayanan yang baik terhadap kebutuhan mahasiswa dan dosen. Pelayanan yang baik juga mencerminkan mutu dari sebuah perguruan tinggi. Pelayanan yang baik yang diberikan oleh universitas atau perguruan tinggi ataupun jurusan kepada mahasiswa, akan meningkatkan kepercayaan masyarakat untuk menitipkan anak-anak di perguruan tinggi atau universitas. Untuk mengetahui feedback dari pelayanan akademik, perlu dilakukan evaluasi terhadap sistem pelayanan akademik. Evaluasi merupakan salah satu rangkaian kegiatan dalam meningkatkan kualitas, kinerja, atau produktivitas suatu lembaga dalam melaksanakan program [1].

Evaluasi terhadap sistem pelayanan akademik dilakukan pada variabel mutu pelayanan dan variabel prosedur pelayanan. Variabel mutu pelayanan terdiri atas kedisiplinan petugas, tanggung jawab petugas, kemampuan petugas, kecepatan pelayanan, keadilan, dan kesopanan serta keramahan petugas. Sedangkan variabel prosedur pelayanan terdiri atas kemudahan prosedur layanan, kesamaan persyaratan dengan jenis pelayanan, kejelasan dan kepastian, kewajaran biaya, kesesuaian biaya yang ditetapkan dengan yang dibayarkan, ketepatan jadwal waktu pelayanan, kenyamanan lingkungan, dan keamanan pelayanan [2]. Untuk melakukan evaluasi terhadap sistem pelayanan akademik, perlu dilakukan survei 
secara langsung kepada dosen, staf administrasi, dan mahasiswa. Survei merupakan instrumen penelitian ilmiah untuk mengumpulkan data primer agar mendapatkan feedback dari responden dengan cara memberikan kuesioner. Dalam pelaksanaan penyebaran kuesioner, STMIK Prabumulih masih menggunakan sistem manual dengan cara mendatangi satu persatu responden sehingga membutuhkan waktu yang lama. Pengelolaan data juga masih menggunakan Microsoft Excel dan aplikasi Statistik yang sering mengakibatkan kesalahan dalam pemasukan dan perhitungan data. Selain itu, STMIK Prabumulih juga harus menyiapkan kuesioner dalam bentuk kertas yang cukup banyak. Hal tersebut membuat STMIK Prabumulih mengeluarkan biaya tambahan.

Agar kuesioner tersaji secara online, maka perlu dibangun sebuah sistem kuesioner berbasis website dengan metode waterfall. Kuesioner ialah kumpulan atau daftar pertanyaan yang dapat digunakan untuk mendapatkan data dari objek penelitian secara langsung [3]. Sedangkan, model air terjun (waterfall) mengambil kegiatan dasar seperti spesifikasi, pengembangan, validasi, dan evolusi serta merepresentasikannya sebagai fase seperti spesifikasi persyaratan, perancangan perangkat lunak, implementasi, pengujian, dan seterusnya [4]. Dari pengembangan menggunakan model waterfall dalam pengembangan sistem informasi kuesioner online, diharapkan komitmen harus dilakukan pada tahap awal proses. Model waterfall harus digunakan hanya ketika persyaratan dipahami dengan baik. Bagaimanapun juga, model waterfall merefleksikan praktik rekayasa. Secara konsekuen, proses perangkat lunak yang berdasarkan pada pendekatan ini masih digunakan untuk pengembangan sistem informasi kuesioner online, terutama jika merupakan bagian dari sistem proyek rekayasa yang lebih besar. Selain itu, proses berdasarkan model waterfall dan pengembangan evolusioner dipakai secara luas untuk pengembangan sistem yang praktis, yang dapat dijadikan batu sandaran dalam pengembangan sistem informasi kuesioner online berbasis website sebagai media feedback terhadap pelayanan akademik pada STMIK Prabumulih ke depannya.

\section{Metode Penelitian}

Penelitian ini menggunakan pendekatan kualitatif yang digunakan untuk mendapatkan data kualitatif berupa profil dari STMIK Prabumulih, sistem yang berjalan, dan pelayanan yang dilakukan oleh staf administrasi STMIK Prabumulih. Data kualitatif tersebut digunakan sebagai bahan pendukung dalam pembangunan kuesioner online. Selanjutnya, pendekatan kuantitatif digunakan untuk memperoleh data kuantitatif berupa rumus perhitungan yang diwujudkan dalam bentuk grafik dalam kuesioner online [5].

\subsection{Teknik Pengumpulan Data}

1. Observasi

Pengumpulan data dengan melakukan pengamatan secara langsung terhadap objek penelitian yang terkait dengan permasalahan yang dibahas, yaitu dengan cara mengunjungi STMIK Prabumulih untuk melihat dan mengamati kegiatan pengisian kuesioner yang dilakukan di STMIK Prabumulih.

2. Wawancara

Dalam hal ini, penulis melakukan proses interaksi dan komunikasi atau tanya-jawab pada pihak-pihak terkait yang memberikan informasi dan dapat memperoleh data-data untuk dipergunakan dalam membangun sistem Kuesioner Online.

3. Dokumentasi

Teknik dokumentasi digunakan untuk mencari sumber informasi yang ada kaitannya dengan penelitian yang berupa dokumen dan foto.

4. Studi Pustaka

Studi kepustakaan dilakukan dengan mencari sumber-sumber pustaka yang mendukung penelitian dan memberikan informasi yang memadai dalam menyelesaikan penelitian ini. Studi kepustakaan yang digunakan antara lain: buku, jurnal, artikel, dan paper.

\subsection{Model Pengembangan Sistem}

Model pengembangan sistem yang digunakan dalam penelitian ini adalah model air terjun atau yang sering disebut dengan istilah waterfall [6]. Terdapat empat tahapan dalam model waterfall yaitu: (1) System Engineering; (2) Analysis; (3) Design; (4) Coding; (5) Testing; (6) Maintenance. Berikut adalah gambaran dari metode waterfall. 


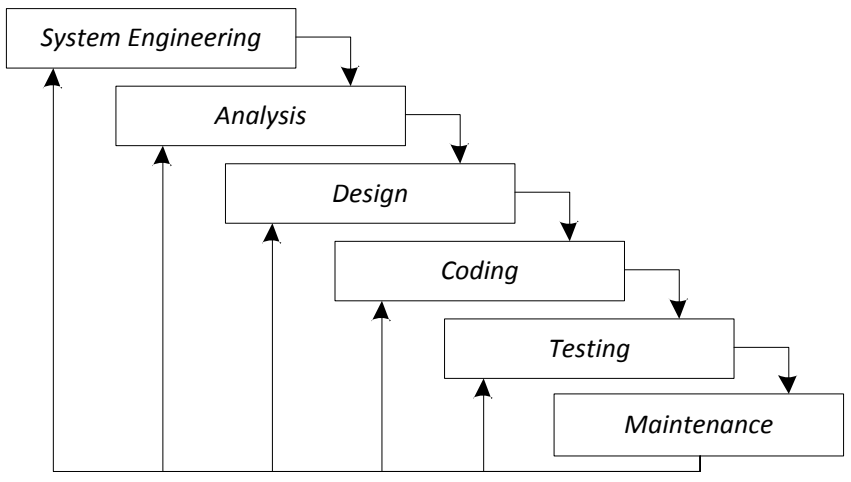

Gambar 1. Model waterfall.

1. System Engineering atau rekayasa sistem yang dilakukan untuk membentuk kebutuhan dari semua elemen sistem dan menganalisis kebutuhan yang di inginkan user, seperti input atau output.

2. Analysis. Analisis kebutuhan sistem dan software yang dilakukan bertujuan untuk menentukan arsitektur sistem secara total dan menentukan ukuran data dan jumlah data.

3. Design yang dilakukan bertujuan untuk menentukan dasar-dasar pembentukan dan pemilihan struktur data, struktur program, arsitektur program, pemilihan algoritma, dan interaksi dengan user.

4. Coding yang dilakukan bertujuan untuk mentransformasikan desain ke dalam baris-baris program dan pemilihan bahasa pemrograman.

5. Testing yang dilakukan untuk menguji kebenaran program.

6. Maintenance yang dilakukan untuk merawat software agar dapat digunakan terus menerus.

\section{Hasil dan Pembahasan}

\subsection{Analisis Sistem berjalan}

Analisis terhadap sistem yang berjalan dilakukan guna untuk mengidentifikasi masalah atau kendala yang ada pada sistem yang telah berjalan. Berikut ialah beberapa kendala dan masalah yang diidentifikasi oleh peneliti pada sistem yang telah berjalan yakni:

Tabel 1. Masalah yang ada pada sistem yang berjalan.

\begin{tabular}{clcl}
\hline No & \multicolumn{1}{c}{ Masalah } & Aktor & \multicolumn{1}{c}{ Solusi } \\
\hline 1 & $\begin{array}{l}\text { Kuesioner yang dirumuskan UMP masih dicetak } \\
\text { sebelum diisi oleh mahasiswa, yang artinya masih } \\
\text { menggunakan kertas yang banyak. }\end{array}$ & UPM & $\begin{array}{l}\text { Menciptakan sistem yang dapat } \\
\text { menggantikan penggunaan kertas } \\
\text { yang banyak tersebut. }\end{array}$ \\
\hline 2 & $\begin{array}{l}\text { Analisis terhadap kuesioner memerlukan waktu yang } \\
\text { lama meskipun melibatkan program analisis, karena } \\
\text { mahasiswa yang mengisi kuesioner berjumlah } \\
\text { banyak, yang artinya input datanya juga banyak } \\
\text { sehingga memerlukan waktu yang lama. }\end{array}$ & UPM & $\begin{array}{l}\text { Perlu diciptakan sistem yang dapat } \\
\text { meminimalkan waktu input data. }\end{array}$ \\
\hline 3 & $\begin{array}{l}\text { Kuesioner tersusun dari soal yang terkadang } \\
\text { menciptakan suasana bosan pada saat mengisi. }\end{array}$ & Mahasiswa & $\begin{array}{l}\text { Diciptakan sistem yang lebih menarik } \\
\text { saat melakukan pengisian kuesioner. }\end{array}$ \\
\hline 4 & $\begin{array}{l}\text { Kuesioner hanya diisi oleh mahasiswa } \\
\text { Kuesioner akan dibuat agar bisa diisi } \\
\text { oleh mahasiswa, dosen, dan staf } \\
\text { administrasi }\end{array}$ \\
\hline 5 & $\begin{array}{l}\text { Data kuesioner dan hasil analisis disimpan secara } \\
\text { softcopy dan hardcopy yang bisa saja hilang jika } \\
\text { perangkat rusak atau hardcopy hilang. }\end{array}$ & UPM & $\begin{array}{l}\text { Perlu dibangun sistem yang } \\
\text { penyimpanan datanya dapat terjaga } \\
\text { dengan baik, salah satu tempat } \\
\text { penyimpanan aman ialah cloud server } \\
\text { atau tempat penyimpanan di internet. }\end{array}$ \\
\hline Sumber: Data primer yang diolah oleh peneliti (2018). & &
\end{tabular}

\subsection{Design Sistem Usulan}

Pada tahapan design sistem usulan ini dibuat rancangan sistem yaitu use case, sequence diagram, dan class diagram. 


\subsubsection{Use Case Diagram}

Sistem usulan untuk proses pengerjaan aliran sistem pengolahan pengisian data kuesioner online yang dilakukan oleh Akto (yang menjalankan sistem) penulis gambarkan pada use case diagram dapat dilihat pada gambar 2 di bawah ini.

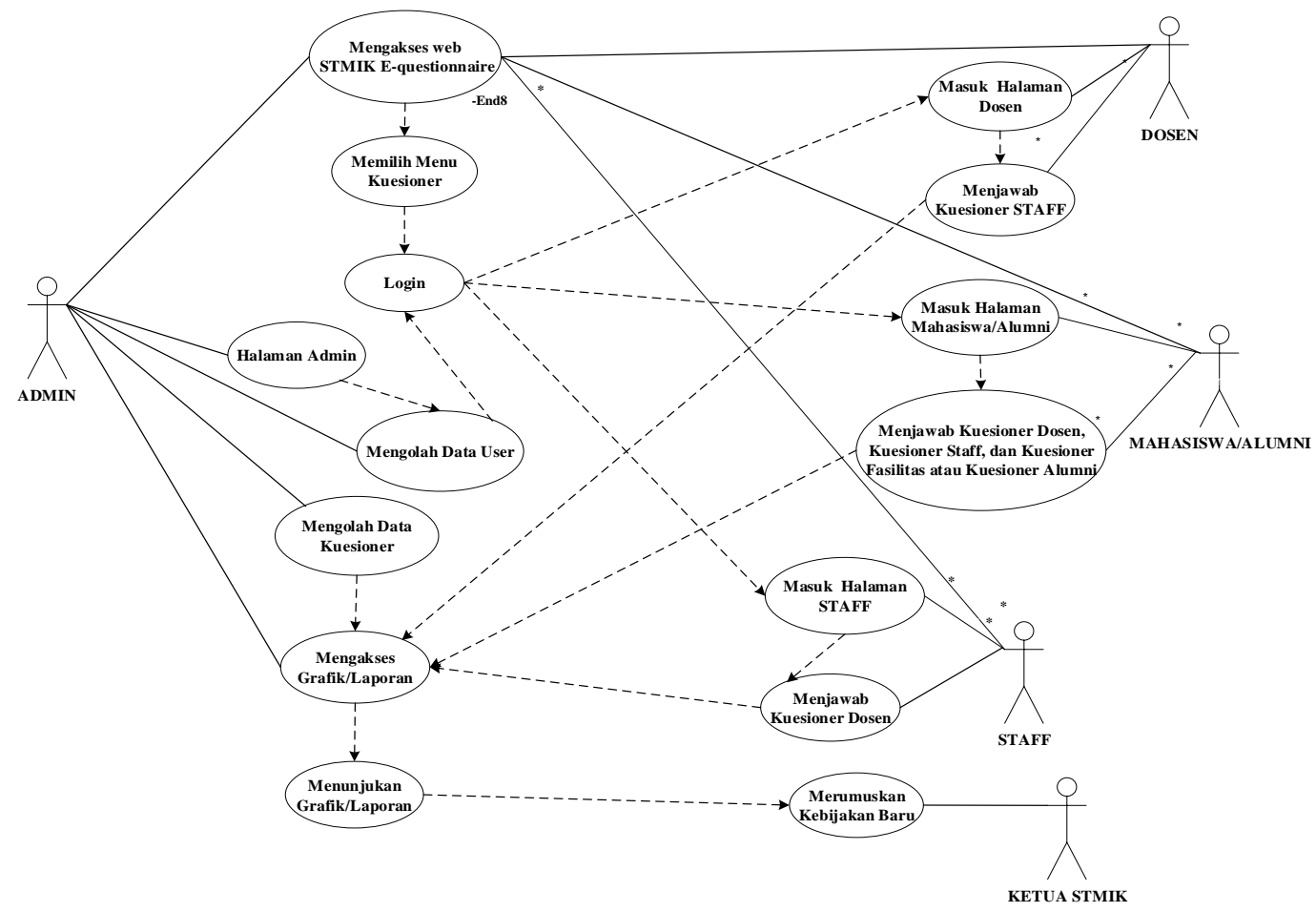

Gambar 2. Use case sistem yang berjalan.

\subsubsection{Sequence Diagram}

\subsubsection{Sequence Diagram Login Admin}

Sequence diagram login admin dimulai ketika aktor Admin menjalankan fungsi untuk login. Sistem memanggil fungsi login() di controller Akun_Admin. Setelah itu melalui fungsi login(), data disimpan ke database sistem dengan memanggil fungsi insert() pada model admin. Sistem akan mengirimkan pemberitahuan jika login gagal. Apabila login berhasil, sistem akan menampilkan menu halaman admin. Pada halaman menu tersebut, admin bisa melalukan pengelolahan data galeri, mahasiswa, dosen, staff, alumni, kuesioner, dan laporan.

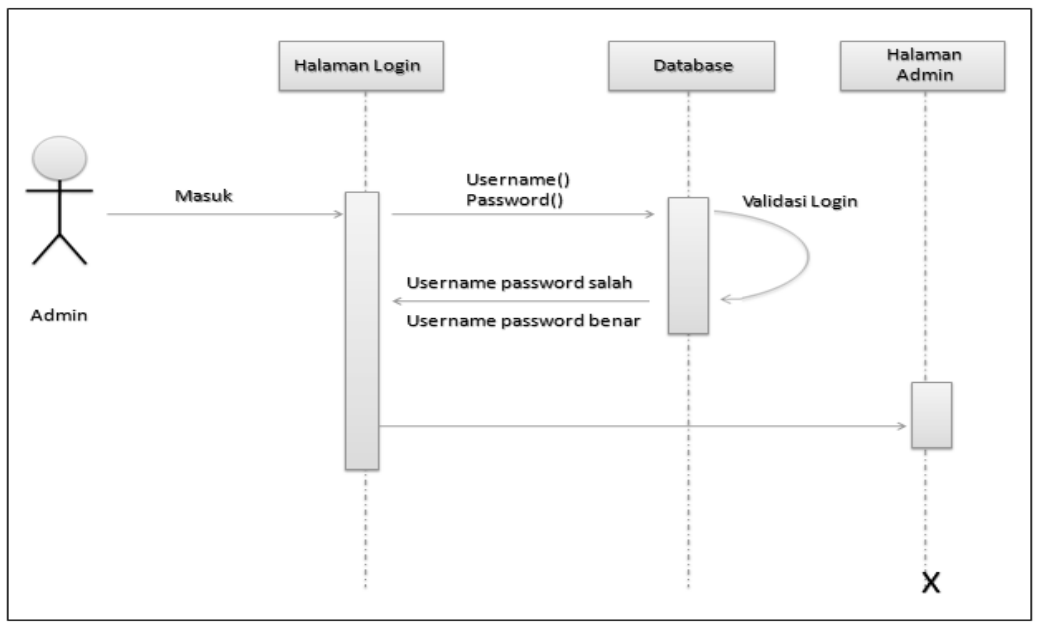

Gambar 3. Sequence diagram login admin. 


\subsubsection{Sequence Diagram Pengisian Kuesioner oleh Dosen}

Sequence diagram pengisian kuesioner oleh dosen dimulai ketika aktor Dosen menjalankan fungsi untuk memilih halaman Kuesioner. Sistem memanggil fungsi halaman kuesioner() di controller Akun_dosen. Setelah itu, dosen akan melakukan pengisian kuesioner melalui fungsi halaman kuesioner(), kemudian data disimpan ke database.

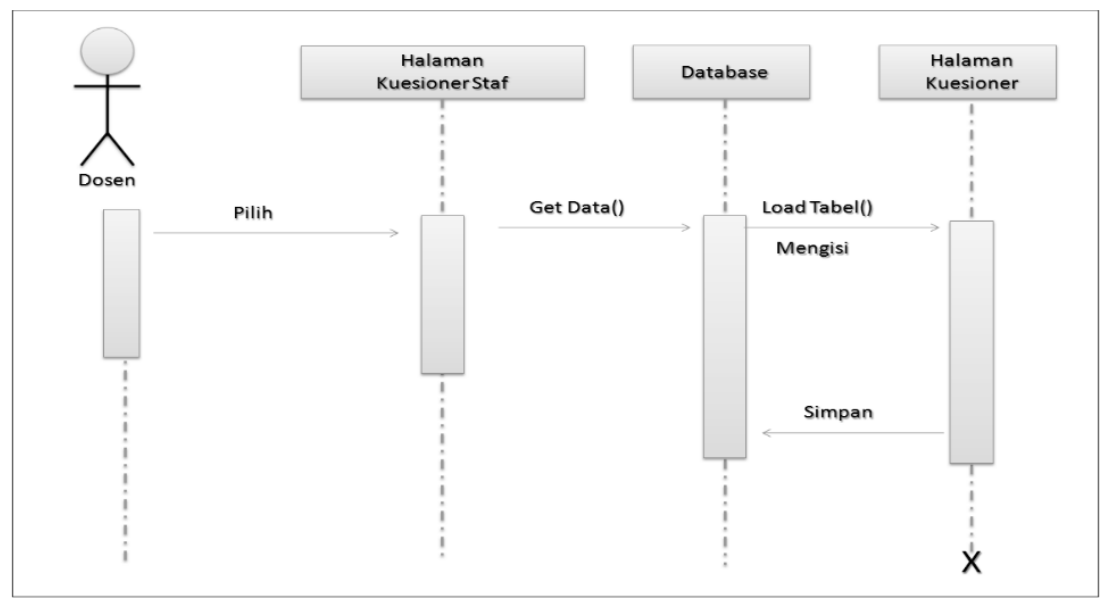

Gambar 4. Sequence diagram pengisian kuesioner oleh dosen.

\subsubsection{Class Diagram}

Class diagram berfungsi untuk menunjukkan class name, atribut, cara kerja, dan hubungan antar kelas pada sistem yang diusulkan. Kelas diagram sistem yang diusulkan, dapat dilihat pada Gambar 5 di bawah ini:

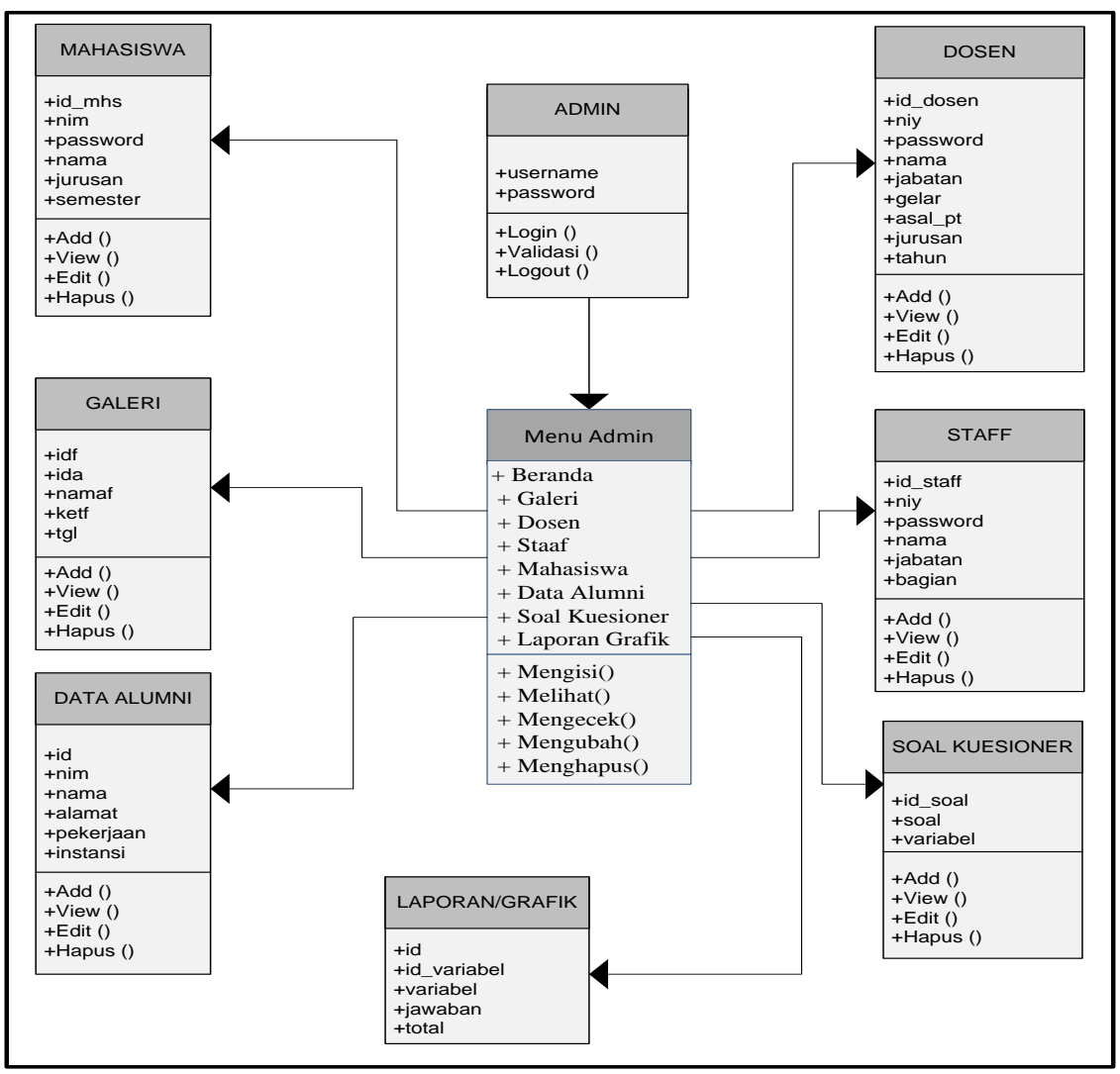

Gambar 5. Class diagram sistem yang diusulkan. 


\subsection{Coding}

Tahapan ini adalah tahapan implementasi atau pembuatan kode program sesuai dengan rancangan sistem dan basis data yang telah dibuat. Penulisan coding (pengkodean) menggunakan bahasa pemrograman PHP dan MySQL sebagai database-nya [7].

\subsection{Implementasi}

Implementasi merupakan tahapan desain atau rancangan yang pada awalnya hanya berupa gambar dari sebuah sistem, diterapkan atau dibangun menjadi sebuah sistem secara utuh yang dapat digunakan untuk efisiensi kinerja bagi sebuah organisasi.

\subsubsection{Implementasi Tampilan Halaman Utama}

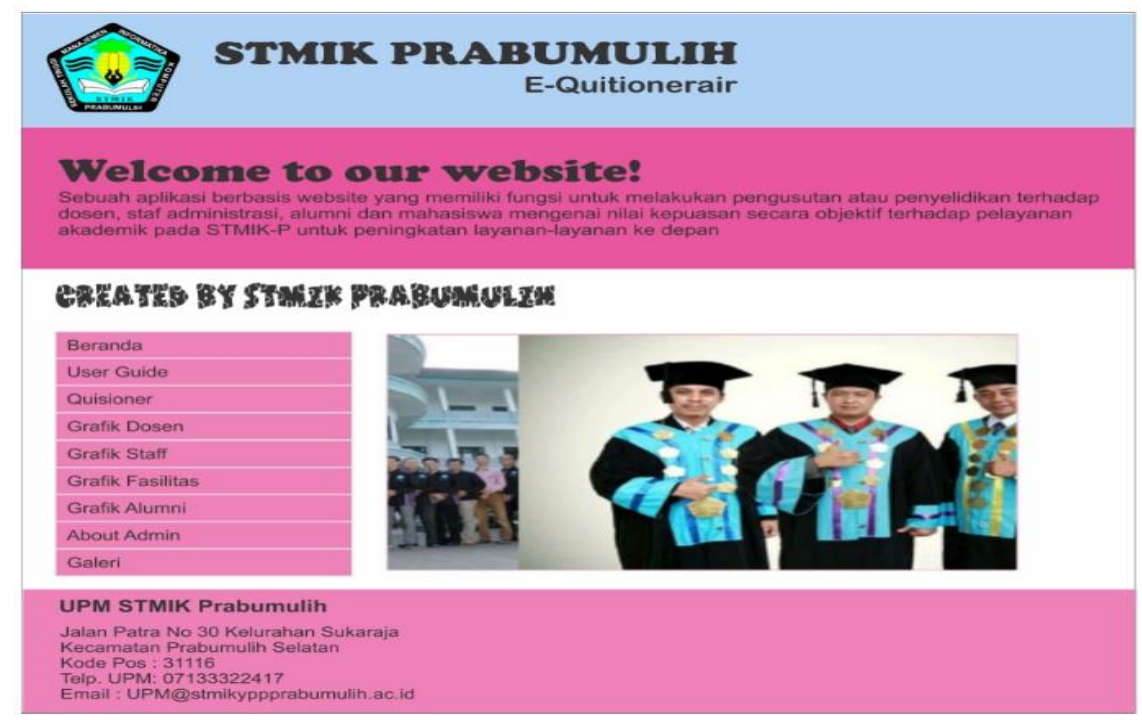

Gambar 6. Halaman utama website.

\subsubsection{Implementasi Tampilan Halaman Login User}

Pada halaman ini, pengguna harus mengisikan username dan password yang telah ditentukan atau yang tersimpan pada database kemudian klik login. Apabila username dan password benar maka pengguna akan masuk ke halaman akun masing-masing dan apabila username dan password salah maka terdapat pesan bahwa data yang dimasukkannya salah dan diarahkan kembali ke halaman login.

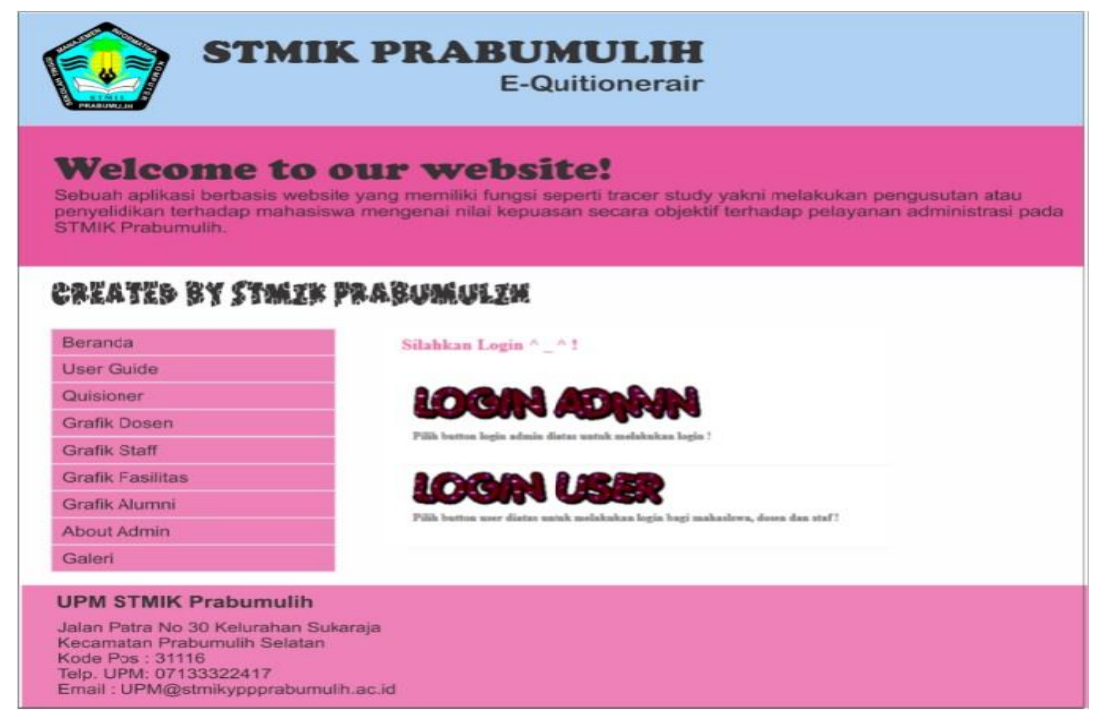

Gambar 7. Halaman depan login. 


\subsubsection{Implementasi Tampilan Halaman Dosen}

Pada Gambar 8 menunjukkan tampilan akun dosen. Pada tampilan ini, dosen bisa mengisi kuesioner untuk staf dan akademik.

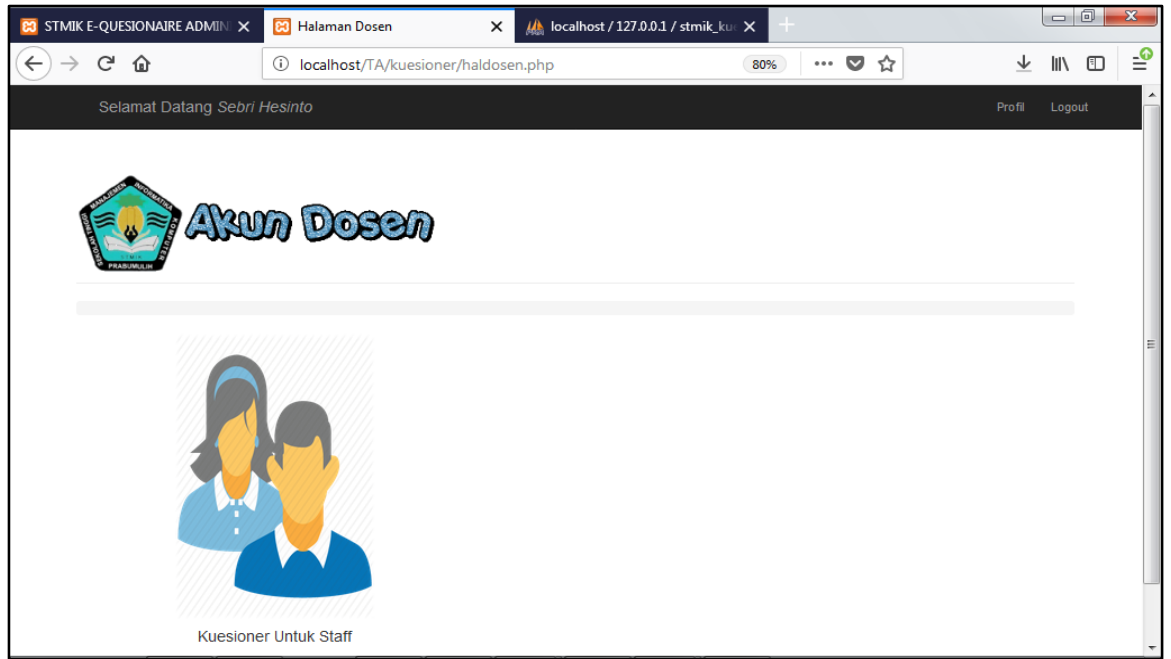

Gambar 8. Halaman dosen.

\subsubsection{Implementasi Tampilan Laporan Analisis Dosen}

Halaman ini terdapat pada halaman admin yang merupakan halaman laporan setelah melakukan input data pada halaman depan laporan. Laporan akan tampil sesuai dengan kategori yang dipilih, misalnya laporan dosen umum, maka yang akan tampil adalah laporan atau grafik dosen umum. Hasilnya dapat dilihat pada Gambar 9.

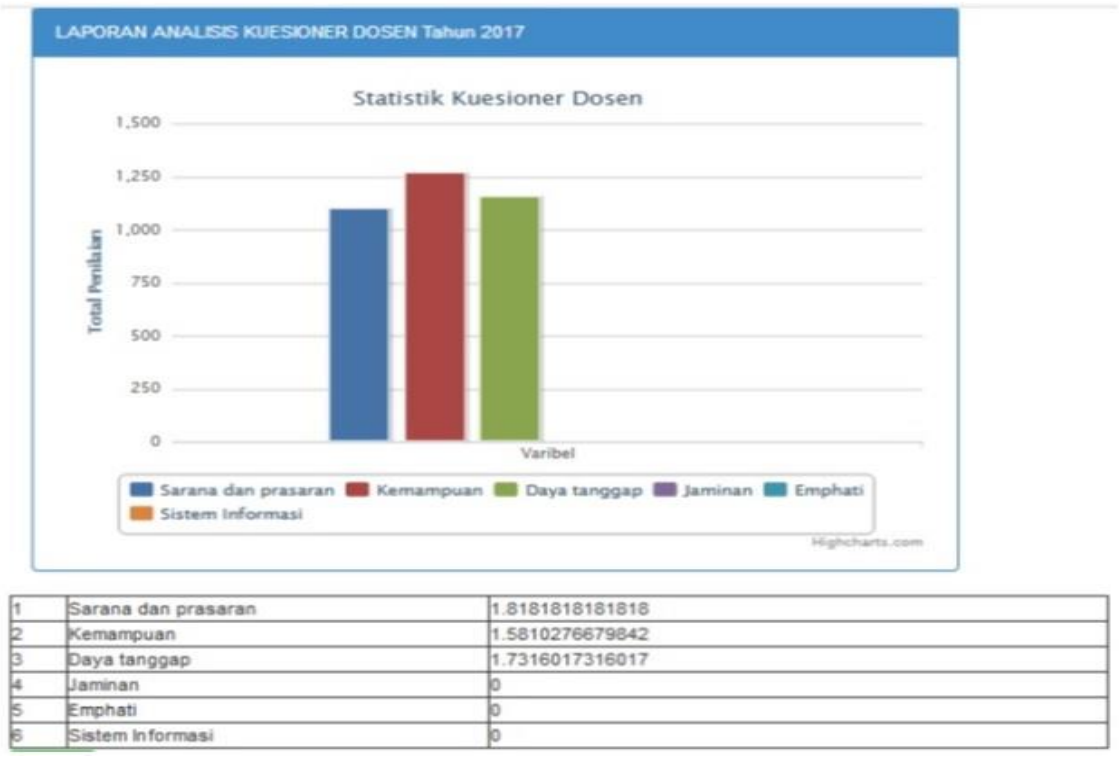

Gambar 9. Grafik/laporan dosen dan staf.

\subsection{Pengujian Sistem}

Dalam membangun sebuah sistem, mungkin saja terdapat beberapa kesalahan. Untuk menemukan kesalahan-kesalahan tersebut, maka perlu dilakukan pengujian terhadap sistem yang telah dibangun. Peneliti akan menggunakan pengujian black-box terhadap sistem STMIK E-questionnaire. Pengujian black-box berfokus pada persyaratan fungsional dari sistem yang telah dibangun atau pengujian dari sudut pandang pengguna tanpa perlu mengetahui proses internalnya. 
Tabel 1. Pengajuan sistem.

\begin{tabular}{|c|c|c|c|}
\hline Item uji & Detail pengujian & Jenis uji & Kesimpulan \\
\hline Login & Verifikasi data login & Black Box & Valid \\
\hline \multirow{4}{*}{ Pengolahan Data Mahasiswa } & Tambah data mahasiswa & Black Box & Valid \\
\hline & Edit data mahasiswa & Black Box & Valid \\
\hline & Hapus data mahasiswa & Black Box & Valid \\
\hline & Search data mahasiswa & Black Box & Valid \\
\hline \multirow{4}{*}{ Pengolahan Data Dosen } & Tambah data dosen & Black Box & Valid \\
\hline & Edit data dosen & Black Box & Valid \\
\hline & Hapus data dosen & Black Box & Valid \\
\hline & Search data dosen & Black Box & Valid \\
\hline \multirow{4}{*}{ Pengolahan Data Staf } & Tambah data staf & Black Box & Valid \\
\hline & Edit data staf & Black Box & Valid \\
\hline & Hapus data staf & Black Box & Valid \\
\hline & Search data staf & Black Box & Valid \\
\hline \multirow{4}{*}{ Pengolahan Data Alumni } & Tambah data alumni & Black Box & Valid \\
\hline & Edit data alumni & Black Box & Valid \\
\hline & Hapus data alumni & Black Box & Valid \\
\hline & Search data alumni & Black Box & Valid \\
\hline \multirow{3}{*}{ Pengolahan Data Pesan Alumni } & Tambah data pesan & Black Box & Valid \\
\hline & Edit data pesan & Black Box & Valid \\
\hline & Hapus data pesan & Black Box & Valid \\
\hline \multirow{4}{*}{ Pengolahan Data mata kuliah } & Tambah data mata kuliah & Black Box & Valid \\
\hline & Edit data mata kuliah & Black Box & Valid \\
\hline & Hapus data mata kuliah & Black Box & Valid \\
\hline & Search data mata kuliah & Black Box & Valid \\
\hline \multirow{4}{*}{ Pengolahan Data Dosen - Mata kuliah } & Tambah data dosen - mata kuliah & Black Box & Valid \\
\hline & Edit data dosen - mata kuliah & Black Box & Valid \\
\hline & Hapus data dosen - mata kuliah & Black Box & Valid \\
\hline & Search data dosen - mata kuliah & Black Box & Valid \\
\hline \multirow{4}{*}{ Pengolahan Data Soal Dosen } & Tambah data soal dosen & Black Box & Valid \\
\hline & Edit data soal dosen & Black Box & Valid \\
\hline & Hapus data soal dosen & Black Box & Valid \\
\hline & Search data soal dosen & Black Box & Valid \\
\hline \multirow{4}{*}{ Pengolahan Data Soal Staf } & Tambah data soal staf & Black Box & Valid \\
\hline & Edit data soal staf & Black Box & Valid \\
\hline & Hapus data soal staf & Black Box & Valid \\
\hline & Search data soal staf & Black Box & Valid \\
\hline \multirow{4}{*}{ Pengolahan Data Soal Fasilitas } & Tambah data soal fasilitas & Black Box & Valid \\
\hline & Edit data soal fasilitas & Black Box & Valid \\
\hline & Hapus data soal fasilitas & Black Box & Valid \\
\hline & Search data soal fasilitas & Black Box & Valid \\
\hline \multirow{4}{*}{ Pengolahan Data Soal Alumni } & Tambah data soal alumni & Black Box & Valid \\
\hline & Edit data soal alumni & Black Box & Valid \\
\hline & Hapus data soal alumni & Black Box & Valid \\
\hline & Search data soal alumni & Black Box & Valid \\
\hline \multirow{3}{*}{ Pengolahan Data Galeri } & Tambah foto & Black Box & Valid \\
\hline & Edit foto & Black Box & Valid \\
\hline & Hapus foto & Black Box & Valid \\
\hline
\end{tabular}

\section{Kesimpulan}

Melalui penelitian yang dilakukan oleh peneliti pada STMIK Prabumulih, dapat disimpulkan bahwa sistem penilaian yang dilakukan oleh STMIK Prabumulih masih manual terhadap pelayanan akademik dengan cara menyebarkan kertas kuesioner kepada mahasiswa, dosen, staf, dan alumni STMIK Prabumulih sehingga banyak menggunakan kertas sehingga tidak efisien. Dengan dikembangkannya Sistem kuesioner online atau STMIK E-questionnaire, dapat diharapkan mampu menjadi media untuk menyampaikan persepsi dosen, staf, dan mahasiswa sebagai feedback terhadap pelayanan akademik yang datanya dapat digunakan untuk mengetahui sejauh mana nilai pelayanan akademik pada STMIK Prabumulih. Sistem ini diharapkan mampu menganalisis jawaban dari kuesioner secara otomatis yang hasilnya akan digunakan sebagai bahan pertimbangan jika perlu dirumuskan kebijakan baru dalam rangka perbaikan dan peningkatan layanan akademik untuk ke depannya.

\section{Daftar Pustaka}

[1] D. Mardapi, "Evaluasi Penerapan Ujian Akhir Sekolah Dasar," Jurnal Penelitian dan Evaluasi Pendidikan, vol. 13, no. 2, pp. 227-245, Desember 2009. 
[2] M. Yola and D. Budianto, "Analisis Kepuasan Konsumen terhadap Kualitas Pelayanan dan Harga Produk pada Supermarket dengan Menggunakan Metode Importance Performance Analysis (IPA)," J. Optimasi Sist. Ind., vol. 12, no. 1, pp. 301-309, 2013.

[3] M. Mansur and K. Kasmawi, "Pengembangan Sistem Database Terpadu Berbasis Web Untuk Penyediaan Layanan Informasi Website Desa,” J. Teknol. dan Sist. Inf., vol. 3, no. 1, 2017.

[4] Christian, A. "Perancangan Sistem Informasi Website Seni Budaya Prabumulih Pada Dinas Pendidikan Dan Kebudayaan Kota Prabumulih”. J InfoTekJar, vol 3, no.1., PP 81-84, 2018

[5] Sugiyono, Metode Penelitian Kuantitatif, Kualitatif dan Kombinasi (Mixed Methods), Bandung: Alfabeta, 2016.

[6] A. Christian, S. Hesinto, and Agustina, "Rancang Bangun Website Sekolah Dengan Menggunakan Framework Bootstrap ( Studi Kasus SMP Negeri 6 Prabumulih ),” Jurnal SISFOKOM, vol. 3, no. 1, pp. 81-84, 2018.

[7] R. Priskila, "Perancangan Sistem Informasi Persediaan Barang Pada Perusahaan Karya Cipta Buana Sentosa Berbasis Web Dengan Metode Extreme," CESS (Journal of Computer Engineering System and Science), vol. 3, no. 2, pp. 94-99, 2018. 